\title{
21. \\ A Vision of Enterprise Integration Considerations
}

A holistic perspective as shown by the Purdue Enterprise Reference Architecture

\begin{abstract}
Hong $\mathrm{Li}^{1}$ and Theodore J. Williams ${ }^{2}$
1. Water-Logic, Inc., 1933 E. Dublin-Granville Rd., \#151, Columbus, OH 43229 USA,

Phone: 614-296-7644

Fax: 866-206-9568, Email: hong@water-logic.com

2. Institute for Interdisciplinary Engineering Studies, Purdue University, 1293 Potter Center, West Lafayette, IN 47907-1293 USA, Phone: 765-494-7434, Fax: 765-494-2351, Email: tjwil@ecn.purdue.edu

Enterprise Integration (EI) is a key concept of Enterprise Engineering (EE) programs. This paper modifies the definition of Enterprise Integration through a broad vision of the field. Typical approaches are studied and reclassified based on recent results from the use of the Purdue Enterprise Reference Architecture. Theories of descriptiveness and prescriptiveness are proposed to support the newly established concept of Approach 2 Architectures as well as their general requirements.
\end{abstract}

\section{INTRODUCTION}

One of the authors wrote years ago that it was unfortunate that the subject of enterprise integration had generally (to date) been presented with a strong technology view only (Williams, 1996a). Although efforts have been made to improve both research and practice in the field of enterprise integration (EI) since then, most solutions offered by scientists and technologists have still (to date) been heavily technically oriented as before, and as so defined, are often not in alignment with management goals in business. Without the justified link with business strategies, even the most advanced information technology could be easily devalued as some pure technical proposals that did not matter much with diminished strategic importance (Carr, 2003).

In this article, the authors will review the key concepts of EI and address some of the open issues in this field. The authors further categorize the current efforts into two different approaches. Then they will emphasize the key characteristics of a holistic approach to EI, which is missing from the purely technical orientation. Under this holistic view, they will also present the focal points of the Purdue Enterprise Reference Architecture (PERA) ${ }^{*}$, including the recent developments in PERA in the hope of calling attention from both academicians and practitioners to reevaluate the present solutions as well as their limits, most of which are still based primarily on electronic connectivity of information only. The business aspects of solutions to EI that have been so far overlooked have actually offered us solid help to think outside the existing technical box and find the right direction to unify

\footnotetext{
* The authors assume that the readers are familiar with PERA and other Type 2 Enterprise Reference Architectures, mainly CIMOSA and GRAI.
} 
technical solutions with business strategies, which indicates why and how EI should be considered more than a pure technical endeavor.

\section{ISSUES IN THE BASIC CONCEPT OF EI}

Many authors have noticed the importance of the business aspects of EI, which are all inclusive in nature. (Petrie, 1992) defined EI as an issue of improvement in enterprise performance. He stated that EI was not "simply a matter of improving connectivity among computer systems". Instead, "EI occurs when there is an improvement in the task-level interactions among people, departments, services, and companies".

Goranson (Goranson, 1992) explained the philosophical aspects of EI in terms of epistemology. He pointed out the epistemology of EI defined the nature of the domain. "This philosophy is, by definition not primarily driven by technical concerns. Rather, business and sociological constraints of information interaction prevail"'.

Vernadat (Vernadat, 1996) commented on a common misconception about EI:

Integration of enterprise activities has long been confused with information system integration under the influence of computer science developments. In fact, activity integration should drive information integration. In other words integration needs must be defined by business users, not by computer scientists!

Vernadat later in the same book gave his definition of $\mathrm{EI}$ as follows:

Enterprise integration is concerned with facilitating information, control, and material flows across organization boundaries by connecting all the necessary functions and heterogeneous functional entities (information system, devices, applications, and people) in order to improve communication, cooperation, and coordination within this enterprise so that the enterprise behaves as an integrated whole, therefore enhancing its overall productivity, flexibility, and capacity for management of change (or reactivity).

Mische (Mische, 2002) also noticed the all-inclusive nature of EI engagements. He too believed that the goal of EI was on the performance improvement side through harmonization and unification among the information processing environment, technologies, human performance, and business processes.

Even with above broad vision of EI, however, definitions of EI explicitly based on connectivity are still common. For example, after Kosanke (Kosanke, 1998) gave a definition of EI based on performance improvement, he soon stated, "The prime goal of enterprise integration is to use information technology for integration of the enterprise operations." (Kosanke, 1999) gave another definition of EI as below:

Enterprise integration: provide the right information at the right place and at the right time and thereby enable communication between people, machines and computers and their efficient cooperation and coordination.

Another typical connectivity-based definition of EI was from the NextGeneration Manufacturing (NGM) Project in US. It (Bloom, 1997) defined EI as

A system that connects and combines people, processes, systems, and technologies to ensure that the right people and the right processes have the right information and the right resources at the right time. 
Given the needs for information integration in the field of EI, the above physically connectivity-based definitions are still correct but in a narrow sense, because technically the common links between components of an enterprise, or between enterprises, are indeed informational in nature. Nevertheless, in reality, connected electronically by the means of information technology does not always mean integrated properly for business at all. The correctness of the physical connectivity is still subject to interpretation. In other words, information integration alone may not necessarily lead to performance improvement (Mische, 2002; Vernadat, 1996; Williams, 1996a; 1996b, and 1999). Information technology as pointed out by many professionals in the field can never be more than an enabler of change (Mische, 2002).

The needs for physical connectivity in the area of EI have grown into a much bigger and richer perspective, Enterprise Interoperability, which is about both information and functionality sharing between concerned parties (Vernadat, 2003). In the above technically oriented definitions of EI, however, the criteria for the right connectivity remain largely unaddressed.

During enterprise development processes, the information description will need to present flows such as decision and control, material, energy, etc. Together they work as the "mortar" for the enterprise in question to hold together its elements or components as the "bricks," such as people, organizations, technologies and related equipment, and business processes, etc., which substantiate the business model and fulfill the business mission.

This same metaphor can be applied to the connections between enterprises. For the tasks of EI, Inter- or Intra-, the focus is on fulfillment of the "building" design through the coordination between all elements, or components. The ingredients of the "mortar" are carefully selected because they have to satisfy the binding requirements, which depend on the business relations in consideration. The "building" architecture must be responsible for managing all relationships including the information architecture.

Associated with the flows discussed above, the existence of many "nonprogrammed" tasks, as defined by Simon years ago (Simon, 1977), presents one of the key issues of information presentation. Note that complexity involved in the enterprise development is often more than the issues of pure formalization because of unstructured and intangible problems that "are sometimes difficult to describe, measure or standardize." (Uppington, 1998)

Even the performance-based definitions of EI may not sufficiently describe the most important functions of EI. Although EI will bring up enterprise-wise performance improvement, localized performance improvement itself may not be sufficiently justifiable as the ultimate driver for EI. In PERA's term (Williams, 1994; 1996b; and 1999) the driver of EI has to be the business mission of the enterprise(s) involved.

The concept of performance improvement may also imply that the enterprise performance could be improved by implementing EI projects after the enterprise systems in question were established, instead of being considered as part of the establishment in the first place. That is, EI could be treated only as an effort after the event. However, that approach has been proved to be less desirable since it may not be always cost-effective. In the viewpoint of PERA, without global considerations, this approach at best may only offer partial results (Rathwell, 1996; 
Williams, 1994; 1996a, 1996b; and 1999). For the same reason, the renovation or disposal of legacy systems should not be considered blindly as localized phenomena either.

A holistic approach will still be desirable even for a performance improvement project. A common mistake in that situation is to concentrate on a localized improvement right from the beginning without a proper investigation on its connections with other systems or subsystems that interact with it, technically and non-technically. In order to prevent the project from failing into a partial result, a global view of the impact from the planned improvement and consequently an alignment between the local improvement and the global objectives from the outset will always be necessary.

Although claims based on physical connectivity may promise readily available and even unlimited connections at the beginning, the inefficiency and ineffectiveness, or even the infeasibility of such initiatives in a real-world setting usually signal an unsustainable solution in the end. In other words, although the narrow focus shared between connectivity-based technical proposals and localized performance improvement projects often makes it possible for the two to go hand in hand, neither of them may well be sufficient to generate the desired global impact once finished.

\section{MODIFICATION OF THE DEFINITION OF EI}

As discussed above, EI should play an integral part at the center of the stage for major enterprise development programs. In terms of business, EI must be dedicated by the top leadership of integration program management where business relations are defined and organized. In terms of technologies, EI must be responsible and accountable for coordination of the multidisciplinary efforts, not depending on any technical implementation paradigm. The basic concepts of EI should prepare both the user community and the suppliers of EI with a viable definition that helps both sides set up a shared vision at the right level. Therefore, the authors feel obligated to restate here our previous definition of enterprise integration (Williams, 1999) as shown below:

\section{Definition of Enterprise Integration:}

Enterprise Integration is the coordination of all elements including business, processes, people, and technology of the enterprise(s) working together in order to achieve the optimal fulfillment of the mission of that enterprise(s) as defined by enterprise management.

This definition does not confine the concept of EI within the area of either operational or any physical connectivity in any predefined manner. The goal of integrating all elements is set specifically for a holistic view of the fulfillment of the business mission based upon decisions made by the management of the enterprise(s). The needed connectivity is not emphasized for the sake of connectivity, but expected as a result of subsequent actions driven by the business requirements.

This definition demonstrates a firm conviction of the authors that the concern for implementation technology is only one of the elements in the integration effort. Clearly with this definition, performance improvement should only be considered a 
means of mission fulfillment of the enterprise(s) in question. Even EI itself is not an end but a means of the mission.

In the early stages of setting up organized efforts to study the issues of EI, one of the major approaches represented by ICEIMT (the International Conference on Enterprise Integration Modeling Technology) was oriented to study only the technical issues or possibilities of computerized technology in EI (Büscher, 1997; Goranson, 1992; 1997; Kosanke, 1998; 1999; and Petrie, 1992). It was understandable that the initial assumption at that time was that computer-based technology, particularly computer-based enterprise modeling, was considered "the key to EI" (Goranson, 1997).

However, after the organized efforts that have been made for more than ten years, the discovery is that the breadth and depth of EI are far beyond mere implementation technology or electronic connectivity. The findings should have been impressive enough to remind the leaders and sponsors of all organizations involved to reconsider the limitations of the initial definitions and orientations. While technical studies of electronic connectivity still remain necessary, open issues beyond technical implementation in the field of EI are already demanding more attention.

Wortmann (Wortmann, 1997) noticed a flaw in the claim of descriptiveness in CIMOSA's approach of computer-based enterprise modeling. People may claim that powerful modern information technology is able to connect or "describe" virtually everything physical with computerized means. However, Wortmann pointed out, the values of such a description would be questionable if it did not prescribe any effective constraints to enforce feasible solutions meaningful in the real world.

\section{REVIEW OF TWO TYPES OF ENTERPRISE REFERENCE ARCHITECTURES}

The International Task Force on Architectures for Enterprise Integration was another major international endeavor exploring approaches to enterprise integration, which started about the same time as ICEIMT. In order to answer the challenge of these open issues, technical and so-called non-technical included, it identified two types of Enterprise Reference Architectures (Williams, 1996c; 1997; and 1999), Type 1 and Type 2.

In terms of the connectivity concern discussed previously, the Type 1 Architectures describe the architecture or physical structure of some component or part of the integrated system such as the computer system or the communications system. They are those that are responsible for carrying out the physical or electronic connections needed by EI. However, Type 1 Architectures themselves must be substantiated through a project or projects that will ensure that the technical implementations will be established properly through a quality program to meet the business needs.

Therefore, the Task Force identified a second type, the Type 2 Architectures that describe the structure of the development and implementation programs themselves. In other words, the Type 2 Architectures are those that are capable of describing the implementation processes of the Type 1 Architectures. In terms of this descriptive capability, they may also be called "Enterprise Models," especially because they are 
about the enterprise entities where the deliverables of Type 1 architectures are produced. A fundamental assumption here is that the process described in this enterprise model will help the enterprises involved develop and then implement the Type 1 Architectures. (Williams, 1996c)

Please note that the differentiation between the two types of architectures was significant because many issues in EI, other than the physical technologies studied by Type 1 Architectures, proved to be more significant as key success factors to the efforts in EI. The definition of the Type 2 Architectures allowed the Task Force to study those key issues arising in the development processes, which are identified as the life cycles of the enterprise development programs or processes.

The Task Force reached a consensus on the importance of the Type 2 Architectures, which later became the foundation of GERAM (Generalized Enterprise Reference Architecture and Methodology) proposal and its requirements as produced by the Task Force. (Bernus, 1996a and Williams, 1997)

Table 1 summarizes the concepts of the two types of Enterprise Reference Architectures. Because the Type 2 Architectures must by definition include technical solutions in all types of the physical forms, the Type 1 Architectures are actually a subset of the Type 2 Architectures as conveniently shown in the form of Set theory in the table.

Table 1. Categorization of enterprise reference architectures

\begin{tabular}{|c|l|l|c|}
\hline Category & \multicolumn{1}{|c|}{ Definition } & Purpose & $\begin{array}{c}\text { Content } \\
\text { Relationship of } \\
\text { the Two Types }\end{array}$ \\
\hline $\begin{array}{c}\text { Type 1 } \\
\text { (T1) }\end{array}$ & $\begin{array}{l}\text { Those which describe an architecture } \\
\text { or physical structure of some } \\
\text { conponent or part of the integrated } \\
\text { system such as the computer system or } \\
\text { the communications system }\end{array}$ & $\begin{array}{l}\text { Direct the development of } \\
\text { technical solutions of EI } \\
\text { and their implementation } \\
\text { tules }\end{array}$ & \multirow{2}{*}{$\mathrm{T} 1 \subset \mathrm{T} 2$} \\
\hline $\begin{array}{c}\text { Type 2 } \\
\text { (T2) }\end{array}$ & $\begin{array}{l}\text { Those which present an architecture or } \\
\text { structure of the project which develops } \\
\text { the physical integration, i.e., those that } \\
\text { illustrate the life cycle of the project } \\
\text { developing the integrated enterprise }\end{array}$ & $\begin{array}{l}\text { Direct the development } \\
\text { process for both technical } \\
\text { and non-technical solutions } \\
\text { of EI and the rules of the } \\
\text { implementation process }\end{array}$ & \\
\hline
\end{tabular}

However, while it was necessary and mutually beneficial, the consensus within the Task Force, which was mainly aimed at the completeness of GERAM, came at a price. The "complete" GERAM, as a big "container" for the three contributing candidate Type 2 Architectures, CIMOSA, GRAI (Doumeingts, 1992a; 1992b; and 2000), and PERA, concealed some fundamental and strategic difference among the candidates. The authors believe that the important difference was rooted in their different visions of EI.

\section{TWO APPROACHES TO EI}

Among the three candidate architectures, CIMOSA and PERA most typically represented the two different approaches to EI. The former has taken an approach of construct-based computerized modeling; the latter an approach of holistic enterprise integration management. The two different approaches to EI can be expressed below: 
- Enterprise integration with construct-based enterprise models and tools represented by CIMOSA, developed by the AMICE Consortium under the ESPRIT Program of the European Community (AMICE, 1993; Kosanke, 1995; 1998; 1999; and Vernadat, 1996; 2003). We will term this as Approach 1 Architecture or Approach 1 hereafter.

- Enterprise integration with holistic enterprise integration management represented by PERA, the Purdue Enterprise Reference Architectures and Methodology (Li, 1994; Rathwell, 1996; and Williams, 1992; 1994; 1996b; $1997 ; 1998 ; 1999)$. We will term this as Approach 2 Architecture or Approach 2 hereafter.

CIMOSA pioneered a novel approach to construct-based enterprise modeling and enterprise integration. As a Type 2 Architecture, CIMOSA developed its Modeling Framework, Integrating Infrastructure, and System Life Cycle in order to guide and support the process of creating a set of computer executable models of a subject enterprise. The intended deliverables from CIMOSA will be computer models that are capable of analyzing, monitoring, and operating the subject enterprise. Given the degree of complexity in EI, the computing power offered by modern science and its achievements should make this approach a very attractive candidate to provide EI.

The CIMOSA computerized modeling approach philosophically has however left itself in a somehow vulnerable position to certain open issues. Wortmann's question on the value of the descriptiveness of CIMOSA models mentioned above (Wortmann, 1997) did reveal a loophole in the enterprise models that CIMOSA offered. Virtually, modern computer technology may present or describe everything. But which of the presentations will be fully capable of becoming reality is most probably beyond what a computer can answer. A computer-executable enterprise model in the virtual world does not necessarily mean a "good enough" operatable enterprise in the real world, which must depend upon physical platforms beyond the discretion of the "virtual reality" presented by computers.

Bernus (Bernus, 1996c and 2002) came to the conclusion that the completeness and consistency of formal machine processed models were insufficient for pragmatic purposes. This conclusion might well indicate again the inherent limit of CIMOSA enterprise models, which would probably never allow the models to take over completely the operations of the subject enterprises as originally promised by the CIMOSA initiatives.

Nell (Nell, 1997) saw that the global impact of enterprise integration was larger than any hardware or software. Therefore, he felt that EI standards should be somewhat platform-independent. Similarly, the International Standard ISO 15704 (ISO 15704, 2000) also acknowledged a broad vision of EI as well as Enterprise Engineering (EE).

Inevitably, as researchers proceed in the field of EI, one has to decide if his efforts should be limited within computerized tools and technology only. Both the power and the limits of computer technologies have to be recognized. The inherent conflict between seemingly omni-descriptiveness and platform-dependent prescriptiveness represents the fundamental limit of CIMOSA's modeling approach.

As an automated aid, computer models will sure help one way or another. But real-world applications always need to have many requirements defined including those "non-programmed", which may well be beyond the descriptive power of 
CIMOSA's construct-based approach. The introduction of the Approach 2 Architecture above signifies to the readers that comprehensive enterprise integration should not always be identified with the construct-based approach.

\section{IDENTIFY A CANDIDATE ARCHITECTURE FOR APPROACH 2}

In order to become a candidate for Approach 2 Architecture, a generic enterprise reference architecture has to satisfy the following two necessary and sufficient conditions:

\section{(1) Descriptiveness of Approach 2 Architecture}

Type 2 Enterprise Reference Architecture that describes the full and complete life cycle of an EE implementation program should be based on the descriptive capacity of the semantics of its architectural formalism. It should not be compromised by any formal syntax of physical or digital machines.

\section{(2) Prescriptiveness of Approach 2 Architecture}

Type 2 Enterprise Reference Architecture that defines a methodology for the full life cycle management should prescribe the generic process paradigm of the life cycle. It should not be compromised by any specific process paradigm of physical or digital implementation.

Each of the two conditions is individually necessary. The first condition defines the requirement for the descriptive capacity of the Approach 2 Architecture. The second condition clarifies the purpose and scope of the descriptive power. They both further state their genericity that is technically independent, which can be consequently summarized in the following theorem:

\section{Theorem 1. (Technical Independence of Approach 2 Architecture)}

The architectural formalism of Approach 2 Enterprise Reference Architecture is independent of implementation technologies.

Since the machine syntax alone may never sufficiently fulfill the descriptive requirements for those unstructured and intangible aspects of an enterprise development program, the restraint of machine excutability must be removed from the definition of an Approach 2 Architecture before it is able to describe complex subjects such as strategic decision making processes or the Human and Organizational Architecture as PERA does.

Note that the first necessary condition does not exclude the formal syntax of machines from the architectural formalism. The machine syntax should be best suitable for the descriptions of those "programmed" (Simon, 1977) procedures. However, whenever the effective and efficient human communications need to be specified, machine languages may never replace the functions of human languages (Dress, 1999 and Rosen, 2000). While it is possible to train humans to understand machine languages, the true challenge to the study of electronic communications does not lie in the direction of letting humans think in terms of machines, but it is the other way around. That is the study of programming the machines so that they could think and communicate like humans. 
As discussed previously, it was the important findings of non-technical factors that have led to the identification and the initiative of Approach 2 Architecture. The principles of generic enterprise architecture and methodology of Approach 2 are turned out fundamentally different from those of implementation concerns with Approach 1. Therefore, they cannot be replaced or interfered by those of Approach 1.

A typical example can be seen through the first two Phases of PERA, Identification of Enterprise Business Entity and Concept (Williams, 1996b; 1997; 1998; and 1999). During the two phases, business strategies that are free from implementation concerns are developed. The forming process of functional considerations will not start until the third phase, which is Definition as shown underlined in Figure 1. In the first two phases, Identification and Concept, there is therefore no room for so-called Function View, Resource View, or Organization View as defined by CIMOSA's Modeling Framework.

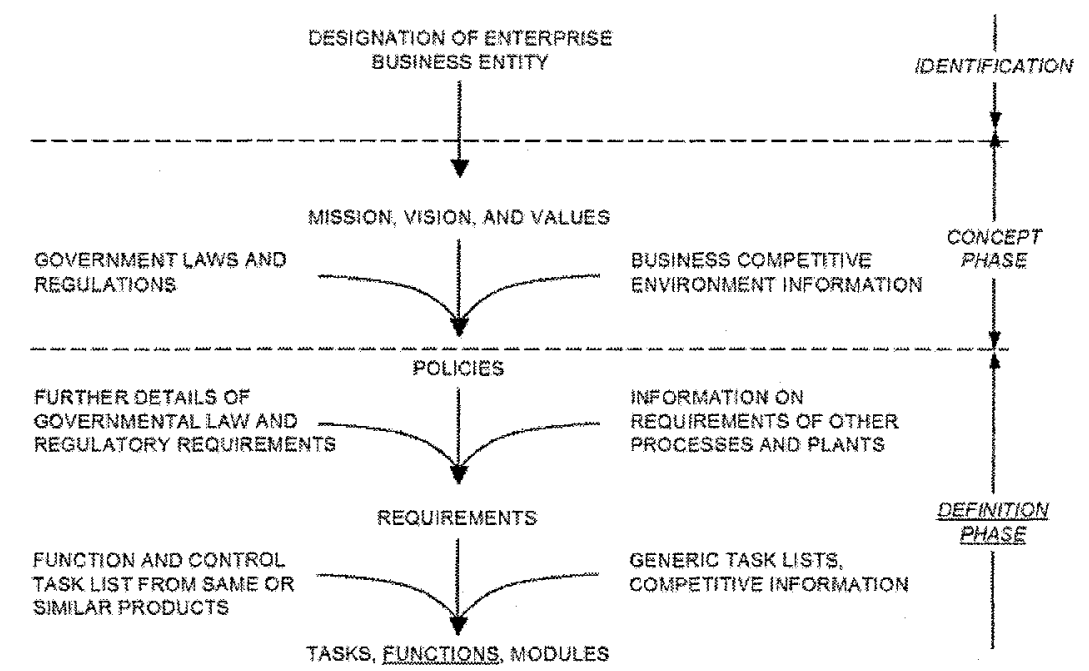

Figure 1 The earliest appearance of Functions in PERA is during the Definition Phase

The approach of CIMOSA's Four Views will be justifiable once the first two phases of PERA deliver the business requirements of "What" to the Definition phase, particularly if the subject enterprise in question is implemented as an IT program. The premature attempt to include the Four Views into the first two phases of PERA is a serious methodological error, which will lead to only two possible consequences. The efforts to fill in those empty Views will either be in vain, or even worse, will violate the principle of the PERA methodology by imposing premature implementation decisions well before the business strategies are formulated. Neither of them could represent the acceptable practice of the PERA Methodology.

The reconfirmation of the technical independence in Theorem 1 above represents the cornerstone of the conceptual integrity of Approach 2 Architecture. The 
definition of EI presented previously by the authors demands that EI be a unifying endeavor between business and technical professionals, between different implementation domains, and between generations of changes, both technical and non-technical included. Only then may a technically independent architectural formalism offer the needed all-embracing capacity.

Business strategies are an inseparable part of the life cycle of enterprise development programs. As Goranson pointed out (Goranson, 2003), the business world is strategically different from the operational world. As shown by PERA methodology, nothing but a technically independent formalism will provide a neutral ground for the communication and cooperation between the two worlds. A similar rationale applies to the communication and cooperation between different technical domains as well.

Requirements from change management represent another important strategic reason for the technical independence of the architectural formalism. Because of the broadness, depth, and dynamics of enterprise development programs, whether an enterprise reference architecture is economically sustainable largely depends on whether it will be able to maintain the stability of its presentation as all kinds of the related implementation paradigms change. Therefore the formalism of the Approach 2 must be able to stay neutral through any future changes in these paradigms.

As a result of the above discussions, another theorem of Approach 2 Architecture can be readily expressed as the following:

\section{Theorem 2. (Organizational Independence of Approach 2 Enterprise Reference Architecture)}

The architectural formalism of Approach 2 Enterprise Reference Architecture is independent of the organizational paradigm of the subject enterprise(s).

Please note that the independency defined in the two theorems may not be reversible. The technical and organizational paradigms of the subject enterprise will be dependent upon the descriptions of the particular Approach 2 Architecture.

The PERA study of enterprise development programs has continued for more than 15 years, because both EI and EE are practically too important to be ignored. Changes in management theories and technology development have become the norm of the day. New business paradigms such as Extended Enterprise, Agile Manufacturing, Virtual Enterprise, etc. emerged in the past ten years one after another (Browne, 1998). The speed of development of new applied technologies in industries seemed to be ever faster. However, "At the end all have to do with enterprise engineering and are contributing to enterprise integration." (Kosanke, 1998)

To be open or interoperatable at the level of enterprise reference architectures with their architectural formalism as defined by PERA (Li, 1994), the broad descriptiveness of an Approach 2 Architecture will make it fully adaptable to those changes. This also enables the methodology so defined to be generic enough to guide EE development programs in any specific industry, process or discrete, and in any specific organization, hierarchical or flat.

\section{PRESCRIPTIVE NATURE OF TYPE 2 ARCHITECTURES}

However, this descriptiveness of Approach 2 Architecture is by no means unlimited. As a Type 2 Architecture, its focus is placed upon the Process Paradigm of the 
implementation process, or the Process Paradigm of the Life Cycle of the EE project in question. Therefore, a theorem deducted from the definitions of Type 2 Architectures and its two Approaches defined in this article can be expressed below:

\section{Theorem 3 (Prescriptiveness of Type 2 Architectures)}

A Type 2 Architecture prescribes its process paradigm of enterprise life cycles, which imposes a constraint on the architectural descriptiveness of the Architecture.

Because the paradigm of the development process will demand the orientation of development organization, we may have a Corollary of organizational paradigm below:

\section{Corollary of Theorem 3 (Organizational Paradigm of Development)}

A Type 2 Architecture prescribes its organizational paradigm of enterprise life cycles based on its process paradigm, which imposes a constraint on the architectural descriptiveness of the Architecture.

Now that we have established the two theorems of Type 2 Architectures, we may have a better understanding of the inherent limit of Approach 1 Architectures since they mainly present the development process in the space of software engineering or IT to develop computer-based models. Given the limitation of the architectural formalism of Approach 1 Architecture, it may at most prove the integrity of a computerized model strictly within its own formal boundary.

Table 2 Categorization of Two Approaches to EI with Type 2 Architectures

\begin{tabular}{|c|c|c|c|}
\hline Category & Definition & Purpose & $\begin{array}{l}\text { Content } \\
\text { Relationship of } \\
\text { the Two Types }\end{array}$ \\
\hline $\begin{array}{l}\text { Approach } 1 \\
\text { (A1) }\end{array}$ & $\begin{array}{l}\text { Those which present an architecture } \\
\text { or structure that illustrate the life } \\
\text { cycle of computer-based enterprise } \\
\text { modeling process }\end{array}$ & $\begin{array}{l}\text { Direct the development of } \\
\text { computerized Enterprise } \\
\text { Models and their } \\
\text { implementation rules }\end{array}$ & \\
\hline $\begin{array}{c}\text { Approach } 2 \\
\text { (A2) }\end{array}$ & $\begin{array}{l}\text { Those which present an architecture } \\
\text { or structure that illustrate the life } \\
\text { cycle of the implementation of } \\
\text { enterprise engineering programs } \\
\text { developing the integrated enterprise }\end{array}$ & $\begin{array}{l}\text { Direct the holistic enterprise } \\
\text { integration development } \\
\text { process for both technical } \\
\text { and non-technical solutions } \\
\text { of EI and the rules of the } \\
\text { implementation process }\end{array}$ & $\mathrm{A} 1 \subset \mathrm{A} 2$ \\
\hline
\end{tabular}

Table 2 summarizes the concepts of the two different Approaches to EI. Because the Approach 1 Architectures are a special type of integration efforts, the Approach 1 Architectures are considered a subset of the Approach 2 Architectures as shown in the form of Set theory in the table.

By comparing the set relations in Table 1Error! Reference source not found. and Table 2, the following relationships of architectural contents can be immediately obtained:

$$
T 1 \subset A 1 \subset A 2
$$

Where, $T 1 \subset T 2 ; A 1 \subset T 2$; and $A 2 \subseteq T 2$. 
As shown in Equation (1), Type 1 Architectures are highly dependent of technical implementations. On the other side of the relationship, Approach 2 Architectures are independent of technical implementations, which allow them to manage the relationships of all types of implementation paradigms for the subject enterprises in question. Equation (1) also indicates that Approach 2 Architectures will accept those implementation paradigms with their detailed concerns under the condition that they should commit those details to the global missions of the subject enterprise(s).

As an Approach 2 Architecture, PERA has a long history of following the path of systems engineering ( $\mathrm{Li}, 1994$ and Williams, 1999). It never self-imposes any constraint from a specific engineering domain. In order to manage the limited space for regular academic publication, the authors have to restrain themselves from more detailed and formal presentation of PERA modeling theories. In the next section, they will however give brief highlights to demonstrate how PERA is able to pass the test of Approach 2 Architecture.

Differentiation between the two Approaches to EI by no means spells an end for what computer models may provide. As a matter of fact, the Approach 1 Architectures represented by CIMOSA have paid their major attention to model the behavior of the subject enterprises to be integrated. Less attention has been given to the behavior of the EE development processes in general, which should not be centered mainly on software engineering processes. It seems that recent researches have regenerated more interest in such studies of the development processes (Cieminski, 2002; Levi, 2002; Nell, 2002a; Webb, 2002; and Weston, 2002).

Initiatives on educational programs of $\mathrm{EI}$ and $\mathrm{EE}$ have been discussed in the research community (Nell, 2002b and Vernadat, 1996). The candidates for hosting the educational programs proposed include Industrial Engineering, Business Management, and Computer Science, etc. Given the broad definition of the Approach 2 Architectures, the authors believe that a Department of Industrial Engineering with modern IE orientation is probably the best place to experiment with these programs since the basic concepts and practice needed for practicing EI or $\mathrm{EE}$ are very close to those of the original orientation of a modern IE department (Rouse, 2004 and Turner, 1993).

\section{HIGHLIGHTS OF PERA AS AN APPROACH 2 ARCHITECTURE}

Being an Approach 2 Architecture, PERA has demonstrated the following key features, which should satisfy the qualifications for the Approach 2 Architecture:

\section{(i) PERA presents a full life cycle of implementing a general enterprise development program.}

Among all three Type 2 Architectures with the Task Force, PERA was considered the most complete one with greatest details (Bernus, 1996b). PERA life cycle was used within the Task Force as the tool to identify enterprise requirements as completely as possible. However, the holistic life cycle model embraced by PERA is much more important than just a checking list for requirements identification for the following reasons: 
- PERA's full life cycle model, with its firm embrace for enterprise Mission, Vision and Values (Williams, 1992 and 1996b), signifies the importance of the decision-making level where the decisions on EE projects should be made. If the broad definition of EI given by the authors previously is acceptable, the scope and depth of its impacts may only be properly appreciated and evaluated at the highest possible position within the organization involved. Decisions at this level are in a "different category" (Nell, 1997) from technical only. Approach 2 Architecture should prepare its users for communications suitable for this level.

- PERA's full life cycle model, with its end-to-end presentation at a proper level of abstraction, demonstrates a strong affinity with the pragmatic patterns of decision-making in business circles. It can also be readily combined with different modern management theories on business life cycles, such as product life cycles, project life cycles, change management, and organizational ecology, etc ( $\mathrm{Li}, 2003)$. Approach 2 Architecture should provide a firm support to justify the integration strategy along with help from other business strategies.

- PERA's full life cycle model, with its detailed step-by-step methodology, also outlines the necessity of closely linking high-level business strategies with implementation solutions. Keeping the technical implementations in alignment with business decisions during EE projects is probably one of the most important missions of a multidisciplinary team of EI. PERA has demonstrated how Approach 2 Architecture should be able to help users turn business strategies into concrete action plans in the context of the project life cycle.

\section{(ii) PERA presents a program methodology that will manage all components of an enterprise, Business, Processes, People and Organization, and Technology.}

The all-inclusive nature of EI demands comprehensive enterprise architectures. In order to manage the embedded complexity, PERA identifies the priorities and dependencies among the components and their integration requirements to ensure seamless integration at the enterprise level as follows:

- PERA acknowledges the general objectiveness of every type of business, and defines the business of the subject enterprise in the form of Mission, Vision, and Values (MVV) to prepare its overall business model in a disciplined manner during the master planning process.

- PERA defines business processes of the subject enterprise directly driven by the defined business MVV to fulfill the necessary business functions and other related business constraints.

- PERA defines a "people architecture," human and organization, in the first place in the process of developing business solutions, by following a fundamental philosophy of automation that is the values of the human being are always above the values of the machine.

- PERA recognizes the needed physical technologies in implementation architectures to develop technical solutions. Technical development however must always respect human and organizational development. This respect in return simplifies the design effort of the implementation architectures.

(iii) PERA presents a descriptive architectural formalism for the EE programs. The descriptiveness of the architectural definition offered by PERA is not about the specifications of a machine-executable language, but fundamentally more about the 
semantic capability of complexity management in general. This is required by the Approach 2 Architecture because of the following reasons:

- Such a "platform-independent" feature allows the Enterprise Architects involved to produce innovative business solutions as much as possible without constraints unnecessarily placed by any existing management paradigm or implementation technology.

- Such a "platform-independent" feature also allows effective and efficient program communications in the multidisciplinary approach required by EI.

- Such a descriptive definition will simplify the change management. Any changes incurred either by a management paradigm shift or by new technology will have a minimum impact on the architectural definitions that are independent of any management paradigm or implementation technology.

- Such descriptiveness will also simplify the program management of the life cycle because it provides a stable foundation for the program decomposition or partition, which does not have to change as another change happens to either the management paradigm or the implementation technology.

The reason for PERA to become such a descriptive architecture is not by an intentional design but is an inevitable result after years of pursuing an approach of systems-engineering style (Checkland, 1999; Klir, 2001; Sage, 1992; 2000; Thomé, 1993; and Williams, 1961) in the field of EI.

The goal of the PERA research has never been to look for a replacement of the current professions. Instead it has been to identify the gaps between the new challenges from the field of EI and the available capabilities of established majors, management and engineering alike. Particularly, being a result of PERA research itself, the principle of "people-first" of PERA (Williams, 1998) commands that PERA entertain the general audience in need in the field of EI.

In order to help implementation of the real-world enterprise development programs, the gap identified was a missing step-by-step guide for Master Planning (Williams, 1992 and 1996b). The best possible process of PERA Master Planning then identified should meet the following requirements:

- The Master Plan should focus on finishing the contents of "What" for the designs of the program involved, which are architecture designs of the subject enterprise without detailed organizational or technical consideration. These "What" designs play the key role of bridging between business requirements and technical specifications.

- After the "What" designs are finished, the Master Plan should then complete the initial assignments of the needed functional carriers, either human or machine, so that more detailed technical or organizational designs will be able to get started.

- The Master Plan should also complete a program management plan for the execution of the Master Plan, including the necessary program decomposition and partition.

- The Master Plan then should be maintained and revisited through program management practice during its execution process.

- Domain-dependent design details, which are about organizational or technical "How," are largely known to professionals within those domains or majors, and therefore should be considered outside the scope of the Master Plan. As a result, the main structure of PERA Master Planning process is kept descriptive. 
As an overarching framework across many different domains or professions, such a domain-independent descriptiveness ensures the integrating capability across those domains under Approach 2 Architecture.

\section{SUMMARY}

The authors present their concerns and conclusions about the major issues of EI and EE. In order to clarify the clouded concepts by pure technical orientation, they restate the definition of EI to demonstrate their holistic view in this field. They also revisit the core concepts of two Types of Enterprise Reference Architectures to further differentiate two different approaches among so-call Type 2 Architectures. The authors introduce a new category, Approach 2 Architecture, to define a broad research area for EI and EE with supporting theories supplied. General requirements including architectural formalism for the Approach 2 Architectures are also discussed to guide further efforts. During the discussions of verifying PERA as an Approach 2 Architecture, the focus is placed upon the business and engineering practicalities of PERA methodology.

\section{REFERENCES}

AMICE (1993) CIMOSA: Open System Architecture for CIM, second revised and extended edition, Springer-Verlag.

Bernus, P. (2002) "Quality of Virtual Enterprise Reference Models" In Enterprise Inter-and Intra-Organizational Integration, Building international consensus, IFIP TC5/WG5.12 International Conference on Enterprise Integration and Modeling Technology (ICEIMT'02), April 24-26, 2002, Valencia, Spain, Kosanke, K., Jochem, R., Nell, J. G., and Ortiz Bas, A., Eds. Kluwer Academic Publishers, Boston, Dordrecht, London, 2003, pp. 135 - 146.

Bernus, P., and Nemes, L. (1996a) "A Framework to Define a Generic Enterprise Reference Architecture and Methodology" Computer Integrated Manufacturing Systems, Vol. 9, No. 3, pp. $179-191$.

Bernus, P, Nemes, L., and Williams, T. J., Eds. (1996b) Architectures for Enterprise Integration, Chapman and Hall.

Bernus, P., Nemes, L., and Morris, B. (1996c) "The Meaning of an Enterprise Model" In Modeling and Methodologies for Enterprise Integration, Bernus, P., and Nemes, L., Eds. Chapman and Hall, London, pp. $182-200$.

Bloom, H. M., (1997) "Enterprise Integration - A United States View" In Enterprise Engineering and Integration: Building international consensus, Proceedings of ICEIMT '97, International Conference on Enterprise Integration and Modeling Technology, Torino, Italy, October 28-30, 1997, K. Kosanke, and J. G. Nell, Eds. Springer, pp. $6-19$.

Browne, J., Goranson, H. T., and Katzy, B., et al. (1998) "Part 1. New Paradigms for the Manufacturing Enterprise" In Handbook of Life Cycle Engineering, Concepts, models, and technologies, Molina, A., Kusiaka A., and Sanchez, J. Eds. Kluwer Academic Publishers, Dordrecht, Boston, London.

Büscher, R. (1997) "Enterprise Integration and Standardization - A European View" In Enterprise Engineering and Integration: Building international consensus, Proceedings of ICEIMT '97, International Conference on Enterprise Integration 
and Modeling Technology, Torino, Italy, October 28-30, 1997, Kosanke, K. and Nell, J. G. Eds., Springer, pp. $3-5$.

Carr, N. G. (2003) "IT doesn't matter" Harvard Business Review, Vol. 81, No. 5, pp. $41-49$.

Checkland, P. (1999) Soft Systems Methodology: a 30-year retrospective, John Wiley and Sons, LTD. Chichester, New York.

Cieminski, G. Macchi, M., and Garettti, M., et al (2002) "Proposal of a Reference Framework for Manufacturing Systems Engineering" In Enterprise Inter-and Intra-Organizational Integration, Building international consensus, IFIP TC5/WG5.12 International Conference on Enterprise Integration and Modeling Technology (ICEIMT'02), April 24-26, 2002, Valencia, Spain, Kosanke, K., Jochem, R., Nell, J. G., and Ortiz Bas, A., Eds. Kluwer Academic Publishers, Boston, Dordrecht, London, 2003, pp. $167-176$.

Doumeingts, G., Vallespir, B., Ducq, Y., and Kleinhans, S. (2000) "Production management and enterprise modelling", Computers in Industry, Vol. 42, Nos. 23 , pp. $245-263$.

Doumeingts, G., Vallespir, B., Zanettin, M., and Chen, D. (1992a) GIM, GRAI Integrated Methodology, A Methodology for Designing CIM Systems, Version 1.0, Unnumbered Report, LAP/GRAI, University Bordeaux 1, Bordeaux, France.

Doumeingts, G., Chen, D., and Marcotte, F. (1992b) "Concepts, models and methods for the design of production management systems", Computers in Industry, Vol. 19, No. 1, pp. $89-111$.

Dress, W. B. (1999) "Epistemology and Rosen's modeling relation", Plenary presentation on the 43rd Meeting of the International Society for the Systems Sciences, June 27 - July 2, 1999, Pacific Grove, California, available at http:/hypernews.ngdc.noaa.gov/hnxtra/Dress paper.html.

Goranson, H. T. (2003) "Architectural support for the advanced virtual enterprise", Computers in Industry, Vol. 51, No. 2, pp. $113-125$.

Goranson, H. T. (1997) "ICEIMT in Perspective - 92 to 97" In Enterprise Engineering and Integration: Building international consensus, Proceedings of ICEIMT '97, International Conference on Enterprise Integration and Modeling Technology, Torino, Italy, October 28-30, 1997, Kosanke, K. and Nell, J. G. Eds. Springer, pp. $167-174$.

Goranson, H. T. (1992) 'The Suppliers' Working Group, Enterprise Integration Reference Taxonomy" In Enterprise Integration Modeling, Proceedings of the First International Conference, Petrie, C. J., Ed. The MIT Press, Cambridge, Massachusetts, London, England, pp. $114-130$.

ISO 15704 (2000) Industrial automation systems - Requirements for enterprisereference architectures and methodologies, International Standards Organization, Geneva.

Klir, G. J. (2001) Facets of Systems Science, 2nd Edition, Kluwer Academic/Plenum Publishers, New York.

Kosanke, K., Vernadat, F., Zelm, M. (1999) "CIMOSA: Enterprise Engineering and Integration," Computers in Industry, Vol. 40, No. 2-3, pp. 83 - 97.

Kosanke, K. and Vernadat, F. B. (1998) "CIMOSA - Life Cycle Based Enterprise Integration" In Handbook of Life Cycle Engineering, Concepts, models, and technologies, Molina, A., Kusiaka A., and Sanchez, J. Eds. Kluwer Academic Publishers, Dordrecht, Boston, London. 
Kosanke, K. (1995) "CIMOSA - Overview and Status," Computers in Industry, Vol. 27, No. 2, pp. $107-109$.

Levi, M. H. (2002) "The Business Process (Quiet) Revolution, Transformation to Process Organization" In Enterprise Inter- and Intra-Organizational Integration, Building international consensus, IFIP TC5/WG5.12 International Conference on Enterprise Integration and Modeling Technology (ICEIMT'02), April 24-26, 2002, Valencia, Spain, Kosanke, K., Jochem, R., Nell, J. G., and Ortiz Bas, A., Eds. Kluwer Academic Publishers, Boston, Dordrecht, London, 2003, pp. 147 158.

Li, H. (2003) Manage Consulting Business with Purdue Enterprise Reference Architecture, Workshop on Applying Enterprise Reference Architecture in Consulting Business, Tsinghua University, Beijing, PR China, Jan. 3-8, 2003.

Li, H. (1994) A Formalization and Extension of the Purdue Enterprise Reference Architecture and the Purdue Methodology, Ph.D. Thesis, Purdue University, West Lafayette, Indiana. Also published as Li, H. and Williams, T. J., A Formalization and Extension of the Purdue Enterprise Reference Architecture and the Purdue Methodology, Technical Report 158, available at http://iies.www.ecn.purdue.edu/IIES/PLAIC/PERA/Publications, Purdue Laboratory for Applied Industrial Control, Purdue University, West Lafayette, IN 47907, April, 1995.

Mische, M. A. (2002) "Defining Systems Integration" In Enterprise Systems Integration, 2nd Edition, Myerson, J. M. Ed. Auerbach Publications, Boca Raton, London, New York, Washington, D. C., pp. 3- 10.

Nell, J. G., delaHostria, E, and Engwall, R. L., et al. (2002a) "System Requirements: Products, Processes and Models" In Enterprise Inter- and Intra-Organizational Integration, Building international consensus, IFIP TC5/WG5.12 International Conference on Enterprise Integration and Modeling Technology (ICEIMT'02), April 24-26, 2002, Valencia, Spain, Kosanke, K., Jochem, R., Nell, J. G., and Ortiz Bas, A., Eds. Kluwer Academic Publishers, Boston, Dordrecht, London, 2003 , pp. $245-252$.

Nell, J. G., and Goranson, H. T. (2002b) "Accomplishments of the ICEIMT'02" In Enterprise Inter-and Intra-Organizational Integration, Building international consensus, IFIP TC5/WG5.12 International Conference on Enterprise Integration and Modeling Technology (ICEIMT'02), April 24-26, 2002, Valencia, Spain, Kosanke, K., Jochem, R., Nell, J. G., and Ortiz Bas, A., Eds. Kluwer Academic Publishers, Boston, Dordrecht, London, 2003, pp. 15 - 23.

Nell, J. G. (1997) "A Standardization Strategy that Matches Enterprise Operation" In Enterprise Engineering and Integration: Building international consensus, Proceedings of ICEIMT '97, International Conference on Enterprise Integration and Modeling Technology, Torino, Italy, October 28-30, 1997, Kosanke, K. and Nell, J. G. Eds., Springer, pp. $54-63$.

Petrie, C. J. (1992) "Introduction" In Enterprise Integration Modeling, Proceedings of the First International Conference, Petrie, C. J., Ed., The MIT Press, Cambridge, Massachusetts, London, England, pp. $1-14$.

Rathwell, G. A. and Williams, T. J. (1996) "Use of the Purdue Enterprise Reference Architecture and Methodology in Industry (the Fluor Daniel example)" In Modeling and Methodologies for Enterprise Integration, Bernus, P., and Nemes, L., Eds. Chapman and Hall, London, pp. $12-44$. 
Rosen, R. (2000) Essays on Life Itself, Columbia University Press, New York, 2000.

Rouse, W. B. (2004) "Embracing the Enterprise", Industrial Engineer Magazine, Vol. 36, No. 3, pp. $31-35$.

Sage, A. P., and Armstrong Jr., J. E. (2000) Introduction to Systems Engineering, John Wiley and Sons, Inc., New York, NY.

Sage, A. P. (1992) Systems Engineering. John Wiley and Sons, Inc., New York, NY.

Simon, H. A. (1977) The New Science of Management Decision, Revised Edition, Prentice-Hall, Inc., Englewood Cliffs, N.J.

Thomé, B., Ed. (1993) Systems Engineering, Principles and Practice of ComputerBased Systems Engineering, John Wiley \& Sons, Inc., New York, NY.

Turner, W. C., Mize, J. H., Case, K. E., and Nasemetz, J. W. (1993) Introduction to Industrial and Systems Engineering, Third Edition, Prentice Hall, Englewood Cliffs, NJ.

Uppington, G. J. (1998) Identifying the Road Ahead: Enhancing and extending the Enterprise Integration Identification Phase, Ph.D. Thesis, Griffith University, Brisbane, Australia.

Vernadat, F. B. (2003) "Enterprise Modeling and Integration, From Fact Modeling to Enterprise Interoperability" In Enterprise Inter-and Intra-Organizational Integration, Building international consensus, IFIP TC5/WG5.12 International Conference on Enterprise Integration and Modeling Technology (ICEIMT'02), April 24-26, 2002, Valencia, Spain, Kosanke, K., Jochem, R., Nell, J. G., and Ortiz Bas, A., Eds. Kluwer Academic Publishers, Boston, Dordrecht, London, pp. $25-33$.

Vernadat, F. B. (1996) Enterprise Modeling and Integration: principles and applications, Chapman and Hall, London, Winheim, New York, Tokyo, Melbourne, Madras.

Webb, P. (2002) "Enterprise Architecture and Systems Engineering" In Enterprise Inter-and Intra-Organizational Integration, Building international consensus, IFIP TC5/WG5.12 International Conference on Enterprise Integration and Modeling Technology (ICEIMT'02), April 24-26, 2002, Valencia, Spain, Kosanke, K., Jochem, R., Nell, J. G., and Ortiz Bas, A., Eds. Kluwer Academic Publishers, Boston, Dordrecht, London, 2003, pp. $159-166$.

Weston, R. H., Ang, C. L., and Bernus, P., et al. (2002) "Virtual Enterprise Planning Methods and Concepts" In Enterprise Inter-and Intra-Organizational Integration, Building international consensus, IFIP TC5/WG5.12 International Conference on Enterprise Integration and Modeling Technology (ICEIMT'02), April 24-26, 2002, Valencia, Spain, Kosanke, K., Jochem, R., Nell, J. G., and Ortiz Bas, A., Eds. Kluwer Academic Publishers, Boston, Dordrecht, London, 2003 , pp. $127-134$.

Williams, T. J. and Li, H. (1999) "PERA and GERAM-Enterprise Reference Architectures in Enterprise Integration" In Information Infrastructure Systems for Manufacturing, Mills, J. J., and Kimura, F., Eds. Kluwer Academic Publishers, Norwell, MA, pp. 3-30.

Williams, T. J. (1998) "Characterization of the Place of the Human in Enterprise Integration" In Handbook of Life Cycle Engineering, Concepts, models, and technologies, Molina, A., Kusiaka A., and Sanchez, J. Eds. Kluwer Academic Publishers, Dordrecht, Boston, London, 1998. 
Williams, T. J. and Li, H. (1997) "The Task Force Specification for GERAM and its Fulfillment by PERA," A. Rev. Control, Vol., 21, pp. 137-147.

Williams, T. J. (1996a) "The needs of the field of integration" In Architectures for Enterprise Integration, Bernus, P, Nemes, L., and Williams, T. J., Eds. Chapman and Hall, pp. $21-31$.

Williams, T. J., Rathwell, G. A., and Li, H., Eds. (1996b) A Handbook on Master Planning Implementation for Enterprise Integration Programs Based on the Purdue Enterprise Reference Architecture and the Purdue Methodology, available at http://iies.www.ecn.purdue.edu/IIES/PLAIC/PERA/Publications, Purdue University, West Lafayette, Indiana, US.

Williams, T. J., Bernus, P., and Nemes, L. (1996c) "The Concept of Enterprise Integration" In Architectures for Enterprise Integration, Bernus, P., Nemes, L., and Williams, T. J., Eds., Chapman and Hall, pp. 9-20.

Williams, T. J. (1994) "The Purdue Enterprise Reference Architecture," Computers in Industry, Vol. 24, Nos 2-3, pp. $141-158$.

Williams, T. J. (1992) The Purdue Enterprise Reference Architecture, Instrument Society of America.

Williams, T. J. (1961) Systems Engineering for the Process Industries, McGraw-Hill Book Company, New York, NY.

Wortmann, J. C. (1997) "Enterprise Reference Architectures - A Research Portfolio" In Enterprise Engineering and Integration: Building international consensus, Proceedings of ICEIMT '97, International Conference on Enterprise Integration and Modeling Technology, Torino, Italy, October 28-30, 1997, Kosanke, K. and Nell, J. G. Eds. Springer, pp. $20-26$ 